\title{
Benefits of Tiotropium/Olodaterol Compared with Tiotropium in Patients with COPD Receiving only LAMA at Baseline: Pooled Analysis of the TONADO ${ }^{\circledR}$ and OTEMTO ${ }^{\circledR}$ Studies
}

Roland Buhl • Dave Singh • Alberto de la Hoz • Wenqiong Xue •

Gary T. Ferguson

Received: January 28, 2020 / Published online: May 27, 2020

(C) The Author(s) 2020, Corrected publication 2022

\section{ABSTRACT}

Introduction: The Global Initiative for Chronic Obstructive Lung Disease (GOLD) strategy report recommends long-acting muscarinic antagonists (LAMA) or long-acting $\beta_{2}$-agonists (LABA) as first-line treatment for chronic obstructive pulmonary disease (COPD), but many patients remain symptomatic on monotherapy and escalation to dual-bronchodilator therapy may be warranted.

Methods: TONADO ${ }^{\circledR} 1 \& 2$ and OTEMTO $^{\circledR} 1 \& 2$ assessed lung function and patient-reported

Digital Features To view digital features for this article go to https://doi.org/10.6084/m9.figshare.12200147.

\footnotetext{
R. Buhl $(\bowtie)$

Pulmonary Department, Johannes Gutenberg

University Hospital, Mainz, Germany

e-mail: Roland.Buhl@unimedizin-mainz.de

D. Singh

Medicines Evaluation Unit, University of Manchester, Manchester University NHS

Foundation Trust, Manchester, UK

A. de la $\mathrm{Hoz}$

Boehringer Ingelheim International $\mathrm{GmbH}$, Ingelheim am Rhein, Germany

W. Xue

Boehringer Ingelheim Pharmaceuticals, Inc., Ridgefield, CT, USA

G. T. Ferguson

Pulmonary Research Institute of Southeast

Michigan, Farmington Hills, MI, USA
}

outcomes in patients with moderate-to-severe (OTEMTO) or moderate-to-very-severe (TONADO) COPD. This pooled post hoc analysis included patients treated with LAMA monotherapy at baseline who were randomised to receive either $5 \mu \mathrm{g}$ tiotropium (LAMA) or $5 / 5 \mu \mathrm{g}$ tiotropium/olodaterol (LAMA/LABA). We assessed changes from baseline and responder rates for trough forced expiratory volume in $1 \mathrm{~s}$ $\left(\mathrm{FEV}_{1}\right)$, St. George's Respiratory Questionnaire (SGRQ) and the Transition Dyspnoea Index (TDI).

Results: Overall, 151 patients received tiotropium; 148 received tiotropium/olodaterol. Mean differences from baseline with tiotropium/olodaterol versus tiotropium were +0.0741 (95\% confidence interval [CI] 0.033, $0.115 ; P=0.0004)$ for trough $\mathrm{FEV}_{1},-2.675$ $(95 \%$ CI $-5.060,-0.291 ; P=0.0280)$ for SGRQ and 1.148 (95\% CI 0.564, 1.732; $P=0.0001)$ for TDI. Patients were more likely to respond when treated with tiotropium/olodaterol versus tiotropium for trough $\mathrm{FEV}_{1}$ (odds ratio [OR] 3.14, 95\% CI 1.94, 5.06; $P<0.0001$ ), SGRQ (OR 1.49, 95\% CI 0.93, 2.40; $P=0.0980)$ and TDI (OR 2.81, 95\% CI 1.71, 4.60; $P<0.0001)$. Minimum clinically important difference from baseline in any of the analysed outcomes $\left(\mathrm{FEV}_{1} \geq 0.1 \mathrm{l}\right.$, SGRQ $\geq 4.0$ points or $\mathrm{TDI} \geq 1.0$ point) was more likely in patients treated with tiotropium/ olodaterol versus tiotropium (OR 2.43, 95\% CI $1.32,4.51 ; P=0.0046)$. 
Conclusion: In patients with COPD receiving only LAMA monotherapy, treatment escalation to tiotropium/olodaterol resulted in statistically significant and clinically relevant improvements in lung function, health status and breathlessness. These results support early therapy optimisation to dual bronchodilation with tiotropium/olodaterol in patients receiving tiotropium alone.

Trial Registration: TONADO ${ }^{\circledR} 1$ was registered in the US National Library of Medicine on 9 September $2011 \quad$ (Clinicaltrials.gov: NCT01431274). TONADO ${ }^{\circledR} 2$ was registered in the US National Library of Medicine on 9 September 2011 (Clinicaltrials.gov: NCT01431287). OTEMTO ${ }^{\circledR} 1$ was registered in the US National Library of Medicine on 17 October 2013 (Clinicaltrials.gov: NCT01964352). OTEMTO ${ }^{\circledR} 2$ was registered in the US National Library of Medicine on 10 December 2013 (Clinicaltrials.gov: NCT02006732).

\section{Graphical Abstract:}

\section{PLAIN LANGUAGE SUMMARY}

- Global recommendations suggest that people with chronic obstructive pulmonary disease (COPD) can start treatment with one of two types of inhaled medicine: either a longacting muscarinic antagonist (LAMA) or a long-acting $\beta_{2}$-agonist (LABA). Doctors can also prescribe these treatments together (LAMA/LABA) if needed.

- To help doctors decide whether to prescribe single or combined treatment, we looked at people with COPD who were taking LAMA alone at the beginning of two large studies $\left(\right.$ TONADO $^{\circledR}$ and OTEMTO ${ }^{\circledR}$ ). In these studies, people with COPD could either stay on LAMA alone (tiotropium) or switch to combined LAMA/LABA treatment (tiotropium/ olodaterol). We looked to see if there were any changes in the functioning of the lungs (measured using forced expiratory volume in

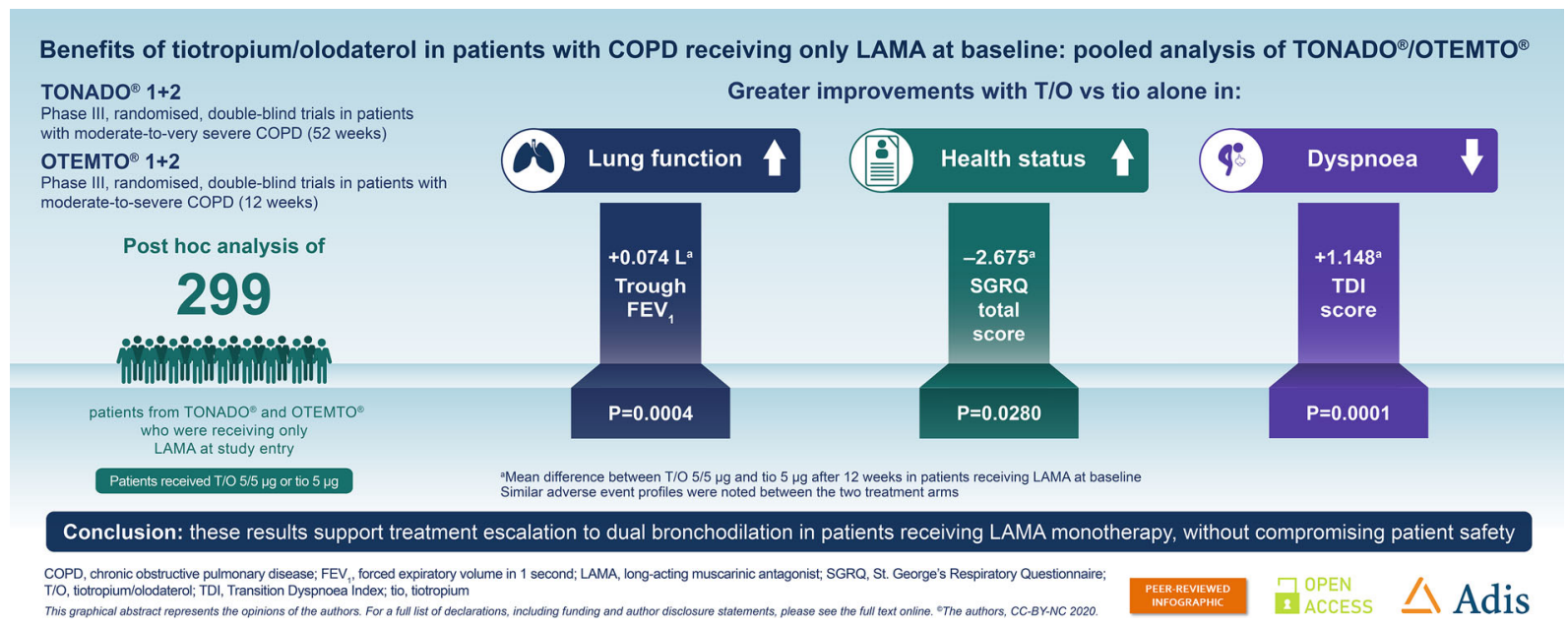


$1 \mathrm{~s}$ ), quality of life (measured using the St. George's Respiratory Questionnaire) or breathlessness (measured using the Transition Dyspnoea Index) between the start of the study and after 12 weeks of treatment.

- We showed that lung function, health-related quality of life and breathlessness were significantly better in people taking tiotropium/olodaterol for 12 weeks compared with those on tiotropium alone. Overall, our results support global recommendations and suggest that many people with COPD who are treated with tiotropium could benefit from stepping up to tiotropium/ olodaterol.

Keywords: Bronchodilator; $\mathrm{FEV}_{1}$; LAMA; OTEMTO; SGRQ; TDI; Tiotropium/olodaterol; TONADO

\section{Key Summary Points}

Why carry out this study?

The Global Initiative for Chronic Obstructive Lung Disease recommends long-acting muscarinic antagonists (LAMAs) or long-acting $\beta_{2}$-agonists (LABAs) as first-line treatment for patients with chronic obstructive pulmonary disease (COPD), with escalation to dualbronchodilator therapy as the next step; however, the American Thoracic Society recommends dual LAMA/LABA bronchodilator therapy over LAMA or LABA monotherapy in patients with COPD who experience dyspnoea or exercise intolerance. The National Institute for Health and Care excellence recommends dual LAMA/LABA therapy for patients with no indication of asthmatic features or corticosteroid responsiveness, who remain breathless or have exacerbations despite optimised non-pharmacological management and use of short-acting bronchodilators.
Previous studies comparing combined LAMA/LABA treatment with LAMA or LABA alone included patients on a range of background therapies, making it difficult to assess the clinical benefit of treatment escalation.

\section{What was learned from the study?}

This pooled analysis, which focused specifically on patients with moderate-tosevere COPD treated with LAMA monotherapy at baseline, showed significantly greater improvements in lung function, health status and breathlessness when treatment was escalated to dual bronchodilation with tiotropium/olodaterol compared with tiotropium alone.

More patients showed a clinically relevant improvement in at least one of the analysed categories (forced expiratory volume in $1 \mathrm{~s}$, St. George's Respiratory Questionnaire or Transition Dyspnoea Index) when treated with tiotropium/ olodaterol (87.7\%) compared with tiotropium (74.5\%).

This study supports the benefits of therapy optimisation to dual bronchodilation with tiotropium/olodaterol in patients receiving tiotropium alone.

\section{INTRODUCTION}

Chronic obstructive pulmonary disease (COPD) is a leading cause of mortality and morbidity [1-4]. In 2016, COPD was the third leading cause of death worldwide, a trend that is anticipated to continue through $2020[5,6]$. Additionally, patients with COPD continue to report reduced quality of life [7].

The current Global Initiative for Chronic Obstructive Lung Disease (GOLD) strategy report recommends a stepwise pharmacological treatment plan for patients with COPD that begins with a long-acting bronchodilator monotherapy (long-acting muscarinic 
antagonists [LAMAs] or long-acting $\beta_{2}$-agonists [LABAs]) as first-line maintenance treatment for most patients, with escalation to dual bronchodilation as the next step [8]. In line with these recommendations, many patients receive initial treatment with LAMAs or, less commonly, LABAs; despite this, many patients treated with monotherapy remain symptomatic [9-13]. The mechanism of action for LAMAs involves blocking the bronchoconstriction effect of acetylcholine, whereas LABAs relax airway smooth muscle by activating $\beta_{2}$-receptors [9]. Therefore, combining these therapies can have complementary and additive effects. Accordingly, the American Thoracic Society 2020 clinical practice guidelines recommend dual LAMA/LABA bronchodilator therapy over LABA or LAMA monotherapy for patients with COPD with dyspnoea or exercise intolerance [14]. Additionally, the National Institute for Health and Care Excellence recommends dual LAMA/LABA therapy for patients with no indication of asthmatic features or corticosteroid responsiveness, who remain breathless or have exacerbations despite optimised non-pharmacological management and use of short-acting bronchodilators [15].

Tiotropium, a once-daily LAMA, has been shown to provide long-term improvements in lung function, quality of life and exercise capacity, along with a reduced risk of exacerbations [7, 10, 16]. Olodaterol, a once-daily LABA with high selectivity for the $\beta_{2}$-adrenoceptor [17], has been combined with tiotropium as a dual therapy (tiotropium/olodaterol) for COPD delivered using the Respimat ${ }^{\circledR}$ inhaler $[2,10,17,18]$. The combination of tiotropium/ olodaterol has been assessed in multiple trials and across different disease severities, demonstrating improvements in lung function, symptoms and quality of life, which has led to its approval for use in many countries worldwide [17-21].

TONADO $^{\circledR} 1 \& 2$ and OTEMTO ${ }^{\circledR} 1 \& 2$ were paired, replicate, double-blind, parallel-group, active-controlled, multicentre, randomised, Phase III studies that included patients with moderate-to-severe (OTEMTO) or moderate-tovery-severe (TONADO) COPD [10, 22]. TONADO previously showed improvements in lung function with acceptable safety profiles over a 52-week period when patients were treated with tiotropium/olodaterol compared with tiotropium or olodaterol monotherapies [10]. OTEMTO also demonstrated improvements in lung function, with an acceptable safety profile in patients treated with tiotropium/olodaterol compared with tiotropium monotherapy or placebo [22].

Previous studies comparing LAMA/LABA with their monotherapies included patients on a range of background therapies $[10,23]$, making it difficult to truly assess the clinical benefit of treatment escalation from one to two longacting bronchodilators. In this pooled analysis, we focused specifically on patients with moderate-to-severe COPD treated with LAMA monotherapy at baseline to assess the effects of treatment escalation to dual-bronchodilator therapy on lung function, symptoms and safety profiles $[10,22]$.

\section{METHODS}

\section{Study Design}

TONADO 1\&2 (NCT01431274 and NCT01431287) and OTEMTO $1 \& 2$ (NCT01964352 and NCT02006732) study designs have previously been described $[10,22]$. The OTEMTO studies included placebo-controlled and comparator-controlled arms; TONADO did not include a placebo-controlled arm.

The current analysis focuses on patients in these trials who were treated with LAMA monotherapy at baseline and subsequently randomised to receive either $5 \mu \mathrm{g}$ tiotropium or $5 / 5 \mu \mathrm{g}$ tiotropium/olodaterol. Treatments were administered once daily with the Respimat ${ }^{\circledR}$ inhaler (Boehringer Ingelheim, Ingelheim am Rhein, Germany).

The study protocols were reviewed and approved by the Independent Ethics Committees and/or Institutional Review Boards of the participating centres. The studies were conducted in accordance with the Declaration of Helsinki and Good Clinical Practice guidelines. Patients in these studies provided written informed consent. 


\section{Study Outcomes and Assessments}

Data were pooled from the TONADO and OTEMTO studies after 12 weeks. Here we assess trough forced expiratory volume in $1 \mathrm{~s}\left(\mathrm{FEV}_{1}\right)$, St. George's Respiratory Questionnaire (SGRQ) total score and Transitional Dyspnoea Index (TDI) focal scores.

Responder rates for these endpoints were also analysed. Responders for trough $\mathrm{FEV}_{1}$ (a change of $>0.1$ l), SGRQ (a decrease of $\geq 4.0$ points) and TDI (an increase of $\geq 1.0$ point versus baseline at the time of analysis) were defined based on the suggested minimum clinically important difference (MCID) for active treatment compared with placebo [10, 24-26].

The adjusted means were obtained from a mixed effects model for repeated measures, which included the fixed effects of treatment, study (TONADO/OTEMTO combined analysis only), planned test day, treatment-by-test day interaction, baseline and baseline-by-test day interaction. A logistic regression model with treatment as covariate was fitted for the responder analysis.

\section{Patients}

The inclusion and exclusion criteria for TONADO and OTEMTO have been previously described [10, 22]. Briefly, patients were aged $\geq 40$ years, with a confirmed diagnosis of moderate-to-severe (OTEMTO) or moderate-tovery-severe (TONADO) COPD, post-bronchodilator $\mathrm{FEV}_{1}<80 \%$ of predicted normal (lower limit $\geq 30 \%$ in OTEMTO; no lower limit specified for TONADO) and post-bronchodilator $\mathrm{FEV}_{1}$ /forced vital capacity $<70 \%$ of predicted. Patients in these studies were either current or ex-smokers with a smoking history of $>10$ pack-years. Patients were not required to be symptomatic to enter the studies. The current analysis includes only patients receiving LAMA maintenance therapy at study entry; patients were excluded from this analysis if they were on any other COPD maintenance therapy (e.g., inhaled corticosteroid [ICS] therapy) at baseline.

Additional subgroup analyses were conducted according to the patient GOLD status; these included GOLD stage 2 and 3 patients, while GOLD stage 4 patients were excluded because of the low number of patients.

\section{RESULTS}

\section{Baseline Characteristics}

Baseline characteristics were collected from 299 patients with moderate-to-very-severe COPD treated with LAMA monotherapy only at baseline; patients on any other maintenance therapy (including ICS) were excluded from the current analyses. Of these, $292(97.7 \%)$ were treated with tiotropium at baseline; $6(2.0 \%)$ were treated with glycopyrronium and $1(0.3 \%)$ patient was treated with aclidinium bromide. As shown in Table 1, baseline characteristics were similar between the two treatment arms (tiotropium/olodaterol and tiotropium), with the exception of weight (mean difference $-4.6 \pm$ $2.29 \mathrm{~kg}$ ) and smoking status (ex-smokers: odds ratio $0.60,95 \%$ confidence interval [CI] $0.38-0.96)$. Additional sensitivity analyses controlling for these covariates did not alter the presented results (data not shown).

\section{Efficacy at Week 12}

\section{Trough FEV}

For trough $\mathrm{FEV}_{1}, 291$ patients were assessed. At week 12, a mean improvement in trough $\mathrm{FEV}_{1}$ from baseline was noted for patients treated with tiotropium/olodaterol $(0.159 \pm 0.015$ l) and those treated with tiotropium $(0.085 \pm 0.015 \mathrm{l})$. The adjusted mean difference between tiotropium/olodaterol and tiotropium was $0.074 \pm 0.021 \quad$ l $\quad(95 \%$ CI $0.033,0.115$; $P=0.0004)$ (Fig. 1).

\section{SGRQ}

In total, 283 patients were included in the SGRQ analysis. Patients showed a mean improvement (reduction in score) when treated with tiotropium/olodaterol $\quad(-5.981 \pm 0.88$ points) or tiotropium monotherapy $(-3.306 \pm 0.88$ points) (Fig. 2). The adjusted mean difference between tiotropium/olodaterol 
Table 1 Patient characteristics at baseline

Tiotropium $5 \mu \mathrm{g}(n=151) \quad$ Tiotropium/olodaterol $5 / 5 \mu \mathrm{g}(n=148)$

Male, $n(\%)$

$109(72.2)$

$99(66.9)$

Mean age, years (SD)

$65.2(8.0)$

$65.9(8.7)$

Weight, kg (SD)*

$76.0(20.6)$

$71.4(18.9)$

Smoking history, $n$ (\%)

Never smoked

$0(0.0)$

$0(0.0)$

Ex-smoker*

97 (64.2)

77 (52.0)

Current smoker*

$54(35.8)$

$71(48.0)$

Smoking pack-years, mean (SD)

48.9 (26.8)

$49.9(23.6)$

Pre-bronchodilator spirometry, mean (SD)

$\begin{array}{ll}\mathrm{FEV}_{1}, 1 & 1.3(0.5)\end{array}$

FVC, 1

Post-bronchodilator spirometry, mean (SD)

$\begin{array}{lll}\mathrm{FEV}_{1}, 1 & 1.5(0.5) & 1.4(0.5) \\ \mathrm{FEV}_{1} \% \text { predicted } & 54.3(14.6) & 54.5(13.8) \\ \text { FVC, } 1 & 3.2(0.9) & 3.1(0.8) \\ \mathrm{FEV}_{1} / \mathrm{FVC}, \% & 47.2(11.5) & 47.3(10.7) \\ \text { SGRQ score } & 39.9(15.9) & 37.5(16.6) \\ \text { BDI score } & 7.0(2.1) & 7.2(1.9) \\ \text { GOLD stage, } n(\%) & & 0(0.0) \\ 1: \mathrm{FEV}_{1} \geq 80 \% & 0(0.0) & 96(64.9) \\ \text { 2: } \mathrm{FEV}_{1} 50-<80 \% & 94(62.3) & 44(29.7) \\ \text { 3: } \mathrm{FEV}_{1} 30-<50 \% & 44(29.1) & 8(5.4) \\ 4: \mathrm{FEV}_{1}<30 \% & 13(8.6) & \end{array}$

BDI, baseline dyspnoea index; $\mathrm{FEV}_{1}$, forced expiratory volume in $1 \mathrm{~s}$; FVC, forced vital capacity; GOLD, Global Initiative for Chronic Obstructive Lung Disease; SD, standard deviation; SGRQ, St. George's Respiratory Questionnaire *Significant differences $(P<0.05)$ were identified between the treatment arms, additional sensitivity analyses controlling for weight and smoking status did not affect the results trend for $\mathrm{FEV}_{1}$, SGRQ or TDI (data not shown)

and tiotropium was calculated as $-2.675 \pm 1.21$ points $\quad(95 \% \quad$ CI -5.060 , $-0.291 ; P=0.0280)$.

\section{TDI}

TDI was assessed in 283 patients through the treatment period and compared with baseline dyspnoea index (BDI). At the end of the 12-week treatment period, patients in both treatment arms showed improvement in their dyspnoea index (mean improvement of $1.911 \pm 0.21$ points for patients treated with tiotropium/olodaterol and $0.763 \pm 0.21$ points for those treated with tiotropium). The adjusted mean difference between tiotropium/olodaterol 


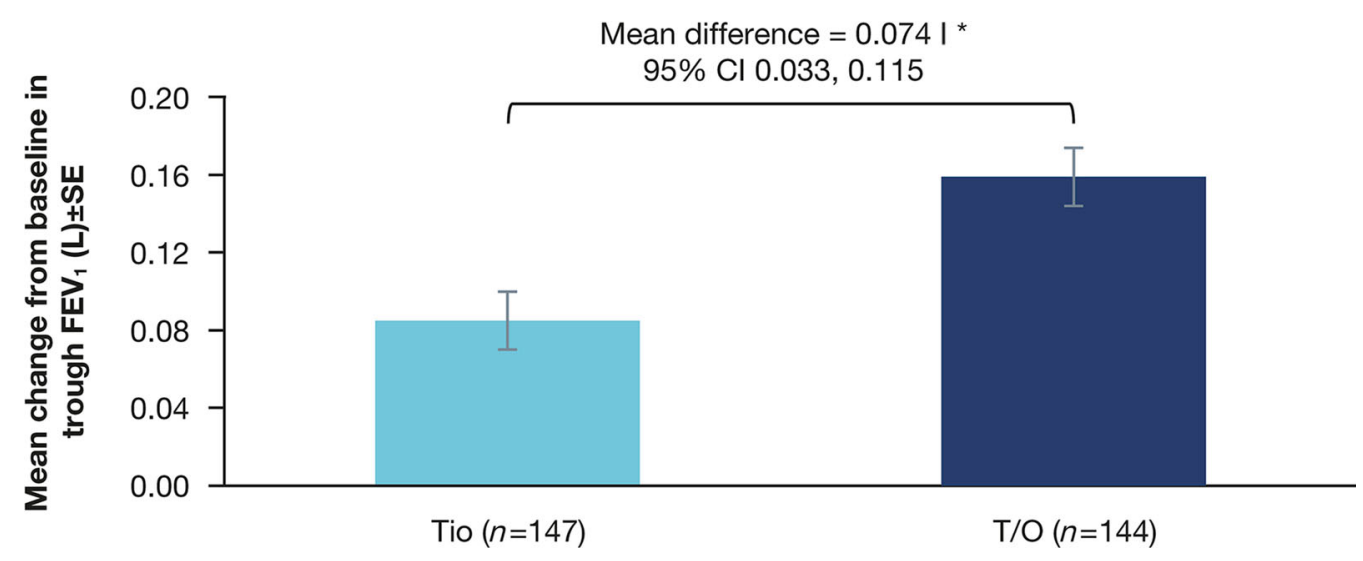

Fig. $1 \mathrm{FEV}_{1}$ change from baseline at 12 weeks. The common baseline mean was calculated as $1.219 \pm 0.029$ 1. ${ }^{*} P=0.0004(P<0.001)$. CI, confidence interval; $\mathrm{FEV}_{1}$, forced expiratory volume in $1 \mathrm{~s}$; SE, standard error; T/O, tiotropium/olodaterol; Tio, tiotropium

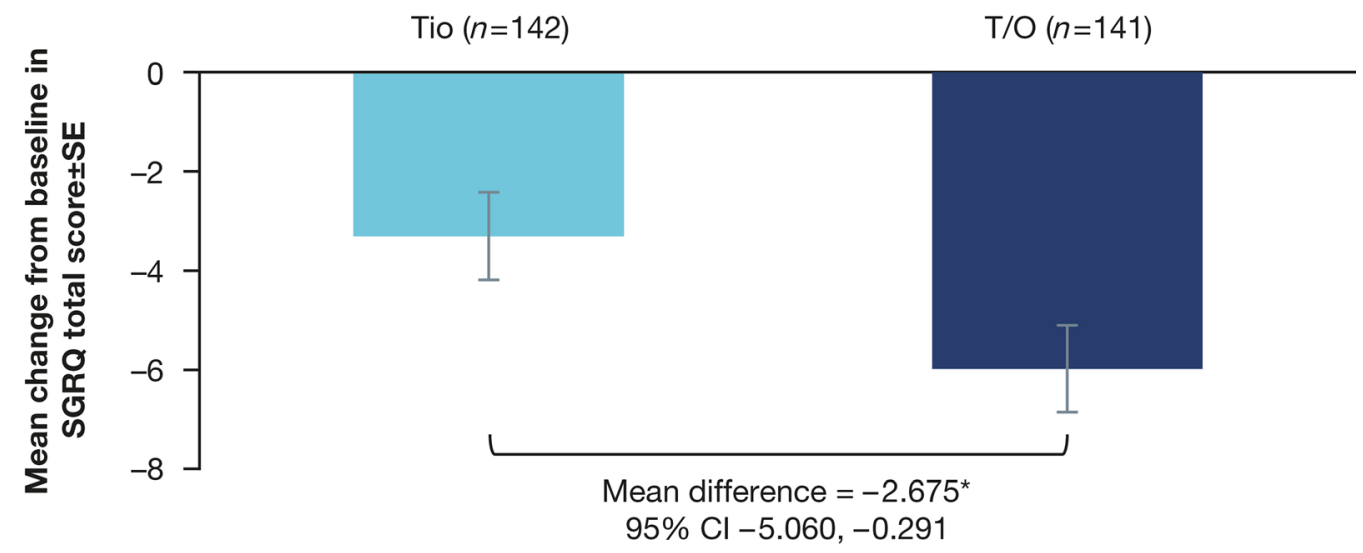

Fig. 2 SGRQ change from baseline at 12 weeks. Common baseline mean for SGRQ was $38.74 \pm 0.972$ points. ${ }^{*} P=0.0280 \quad(P<0.05) . \mathrm{CI}$, confidence interval; SE,

and tiotropium was calculated as $1.148 \pm 0.30$ (95\% CI 0.56, 1.73; $P=0.0001$ ) (Fig. 3).

\section{Responder Rates}

\section{Trough FEV}

At the end of week 12, more patients treated with tiotropium/olodaterol $(n=100 ; 68.5 \%)$ showed a response in trough $\mathrm{FEV}_{1}$ (an increase of $>0.1 \mathrm{l}$ in $\mathrm{FEV}_{1}$ ) than patients treated with tiotropium ( $n=61 ; 40.9 \%)$ (Fig. 4$)$. At the end of the 12-week treatment period, the responder odds ratio for $\mathrm{FEV}_{1}$ was $3.14 \pm 0.77 \mathrm{l}(95 \% \mathrm{CI}$ 1.94, 5.06; $P<0.0001)$. standard error; SGRQ, St. George's Respiratory Questionnaire; $\mathrm{T} / \mathrm{O}$, tiotropium/olodaterol; Tio, tiotropium

\section{SGRQ}

In total, $81(57.4 \%)$ patients treated with tiotropium/olodaterol and 68 (47.9\%) patients treated with tiotropium met the SGRQ responder criteria (a decrease of $\geq 4$ points in SGRQ) (Fig. 4). The responder odds ratio for SGRQ score was $1.49 \pm 0.36(95 \%$ CI $0.93,2.40$; $P=0.0980$ ) when comparing patients treated with tiotropium/olodaterol with patients treated with tiotropium.

TDI

Eighty $(57.1 \%)$ patients treated with tiotropium/olodaterol and $43(31.5 \%)$ patients treated with tiotropium were classed as TDI 


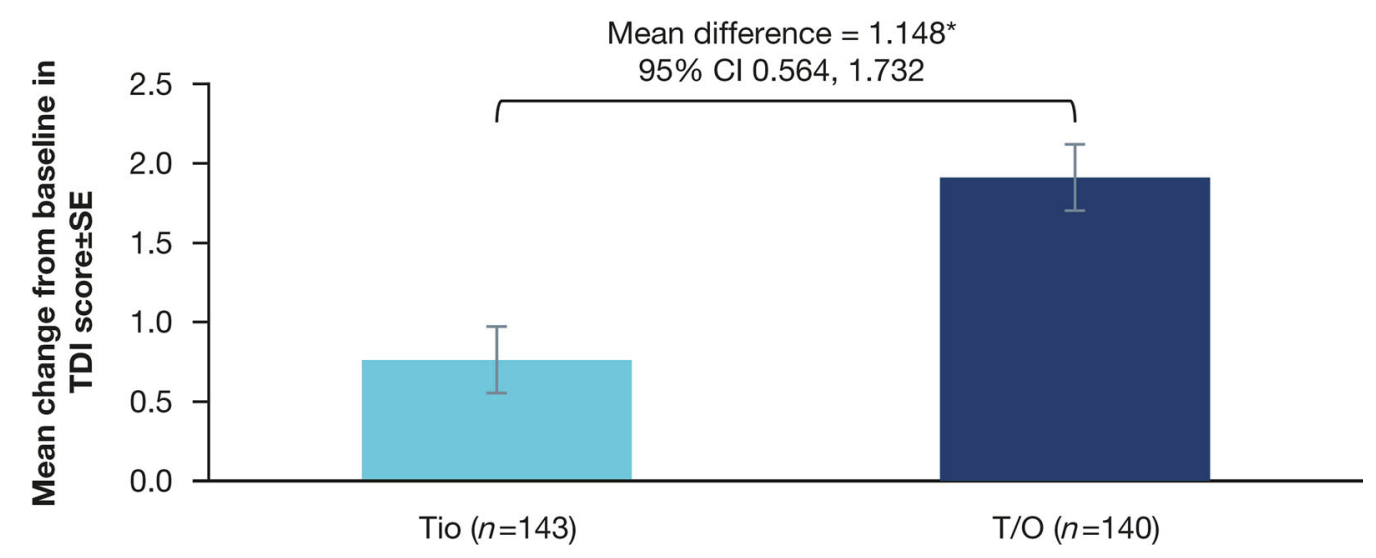

Fig. 3 TDI change from baseline at 12 weeks. At baseline, patients from the TONADO and OTEMTO trials showed a combined baseline mean of $7.138 \pm 0.117$ points. ${ }^{*} P=0.0001$. CI, confidence interval; SE, standard error; T/O, tiotropium/olodaterol; TDI, Transition Dyspnoea Index; Tio, tiotropium

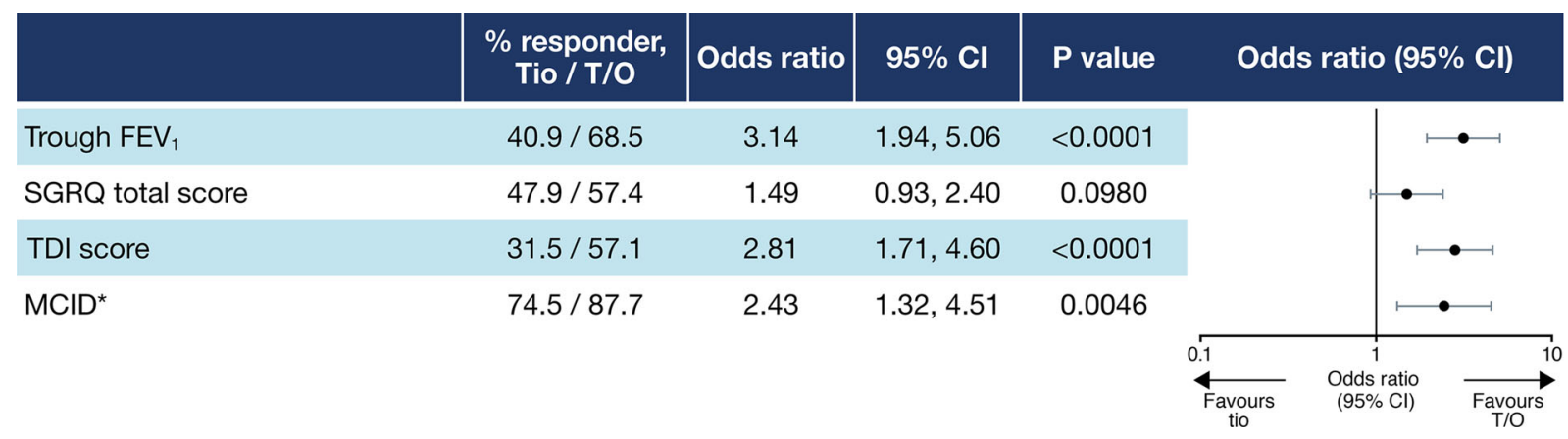

Fig. 4 Assessed responder rates after 12 weeks. ${ }^{*}$ MCID in at least one of the assessed outcomes $\left(\mathrm{FEV}_{1} \geq 0.1 \mathrm{l}\right.$, SGRQ $\geq 4.0$ points or TDI $\geq 1.0$ point). CI, confidence interval; $\mathrm{FEV}_{1}$, forced expiratory volume in $1 \mathrm{~s}$; MCID,

responders (TDI focal score $\geq 1$ point higher than their respective BDI) (Fig. 4). The overall odds ratio for TDI responders was $2.81 \pm 0.71$ (95\% CI 1.71, 4.60; $P<0.0001)$.

\section{Patients with MCID}

Of the overall population, $128(87.7 \%)$ patients treated with tiotropium/olodaterol and 111 (74.5\%) patients treated with tiotropium experienced an MCID from baseline in at least one of the analysed outcomes (FEV 1 , SGRQ or TDI). The subjects with at least one MCID from the analysed outcomes after 12 weeks showed an odds ratio of $2.43 \pm 0.77$ (95\% CI 1.32, 4.51; minimum clinically important difference; SGRQ, St. George's Respiratory Questionnaire; T/O, tiotropium/ olodaterol; TDI, Transition Dyspnoea Index; Tio, tiotropium

$P=0.0046)$ in favour of tiotropium/olodaterol (Fig. 4).

\section{Subgroup Analysis by GOLD Status}

Additionally, patients were analysed for MCID in at least one of the analysed outcomes according to their GOLD stage. This subgroup analysis included a small subpopulation of 186 GOLD stage 2 patients (92 treated with tiotropium and 94 treated with tiotropium/olodaterol). Of these, $80(85.1 \%)$ patients treated with tiotropium/olodaterol and 72 (78.3\%) patients treated with tiotropium achieved the MCID in at least one of the analysed outcomes. Similar trends were shown when assessing a 
small subpopulation of 88 GOLD stage 3 patients, with MCID being achieved in at least one of the analysed outcomes in 40 (90.9\%) patients treated with tiotropium/olodaterol and $30(68.2 \%)$ patients treated with tiotropium at the end of the 12-week treatment period (Fig. 5). The calculated odds ratio was $1.59 \pm 0.61(95 \%$ CI $0.75,3.37 ; P=0.2295)$ for GOLD stage 2 and $4.67 \pm 2.88$ (95\% CI 1.40, $15.62 ; P=0.0124)$ for GOLD stage 3 . GOLD stage 4 patients were omitted from the subgroup analysis because of the low number of patients (13 tiotropium-treated patients and 8 tiotropium/olodaterol-treated patients); however, of the GOLD 4 patients, 9 (69.2\%) tiotropium-treated patients and 8 (100.0\%) tiotropium/olodaterol-treated patients achieved an MCID in at least one of the analysed outcomes.

\section{Safety}

Table 2 shows a summary of adverse events (AEs) for the combined data set (studies NCT01431274, NCT01431287, NCT01964352 and NCT02006732). AE incidence was similar between the two treatment arms, with most AEs being mild or moderate. In the tiotropium arm, $71.5 \%$ of patients reported at least one $\mathrm{AE}$ versus $63.5 \%$ of patients in the tiotropium/olodaterol arm. In the two treatment arms, a similar number of patients reported drug-related AEs: six $(4.0 \%)$ patients in the tiotropium arm and seven $(4.7 \%)$ patients in the tiotropium/olodaterol arm. Similar rates of serious AEs were reported in the two treatment arms: $18(11.9 \%)$ patients treated with tiotropium and 15 (10.1\%) patients treated with tiotropium/olodaterol.
One fatal serious AE was reported in the tiotropium/olodaterol arm ( $0.7 \%$ of patients).

The incidence of respiratory events was similar between the two treatment arms, occurring in $46(30.5 \%)$ patients in the tiotropium arm and $42(28.4 \%)$ patients in the tiotropium/olodaterol arm.

\section{DISCUSSION}

Long-acting bronchodilators remain a key firstline therapy for COPD maintenance [8,27], but many patients remain symptomatic on monotherapy [9-13]. This post hoc analysis focused on a subset of patients from the TONADO and OTEMTO studies with moderateto-severe COPD who were treated with only LAMA monotherapy at baseline $[10,22]$. Patients were excluded if they were currently on any other maintenance treatment. After 12 weeks, optimisation of treatment with tiotropium/olodaterol dual-bronchodilator therapy provided greater improvements in lung function (trough $\mathrm{FEV}_{1}$ ), health status (SGRQ) and dyspnoea severity (TDI) compared with continuing LAMA monotherapy. These results support treatment escalation from LAMA monotherapy to dual-bronchodilator treatment (as recommended in the GOLD management strategy [8]) to optimise lung function, achieve better symptom control and improve patient quality of life.

We observed a greater likelihood of achieving an MCID in at least one of the outcomes (i.e., any trough $\mathrm{FEV}_{1}$, SGRQ or TDI improvements) in patients treated with tiotropium/ olodaterol compared with patients treated with

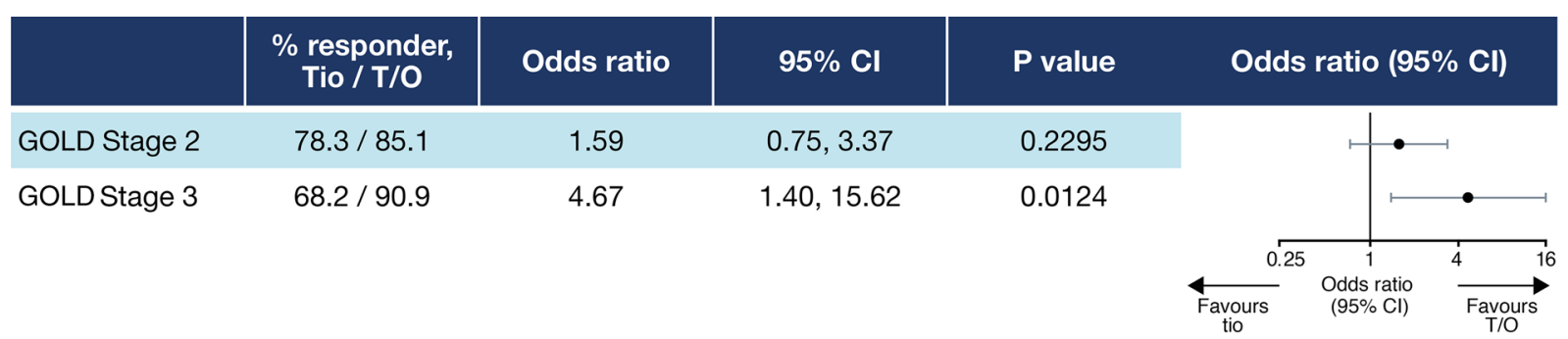

Fig. 5 Subgroup analysis of responder rates by GOLD stage. CI, confidence interval; GOLD, Global Initiative for Chronic Obstructive Lung Disease; T/O, tiotropium/olodaterol; TDI, Transition Dyspnoea Index; Tio, tiotropium 
Table 2 Summary of adverse events: combined analysis (treated set)

\begin{tabular}{|c|c|c|}
\hline & $\begin{array}{l}\text { Tiotropium } \\
5 \mu \mathrm{g} \\
(n=151)\end{array}$ & $\begin{array}{l}\text { Tiotropium/ } \\
\text { olodaterol } 5 / 5 \mu \mathrm{g} \\
(n=148)\end{array}$ \\
\hline \multicolumn{3}{|l|}{ Patients with: $n(\%)$} \\
\hline Any AE & $108(71.5)$ & $94(63.5)$ \\
\hline Severe AEs & $15(9.9)$ & $15(10.1)$ \\
\hline $\begin{array}{l}\text { Investigator-defined } \\
\text { drug-related AEs }\end{array}$ & $6(4.0)$ & $7(4.7)$ \\
\hline $\begin{array}{l}\text { AEs leading to } \\
\text { discontinuation }\end{array}$ & $10(6.6)$ & $4(2.7)$ \\
\hline $\begin{array}{l}\text { Patients with serious } \\
\text { AEs }\end{array}$ & $18(11.9)$ & $15(10.1)$ \\
\hline Fatal & $0(0.0)$ & $1(0.7)$ \\
\hline Life-threatening & $0(0.0)$ & $0(0.0)$ \\
\hline $\begin{array}{l}\text { Disability/ } \\
\text { incapacitation }\end{array}$ & $1(0.7)$ & $0(0.0)$ \\
\hline $\begin{array}{l}\text { Required } \\
\text { hospitalisation }\end{array}$ & $17(11.3)$ & $13(8.8)$ \\
\hline $\begin{array}{l}\text { Prolonged } \\
\text { hospitalisation }\end{array}$ & $0(0.0)$ & $0(0.0)$ \\
\hline Other & $3(2.0)$ & $1(0.7)$ \\
\hline $\begin{array}{l}\text { Infections and } \\
\text { infestations }\end{array}$ & $51(33.8)$ & $51(34.5)$ \\
\hline $\begin{array}{l}\text { Viral upper } \\
\text { respiratory tract } \\
\text { infection }\end{array}$ & $17(11.3)$ & $20(13.5)$ \\
\hline Sinusitis & $0(0.0)$ & $8(5.4)$ \\
\hline Bronchitis & $5(3.3)$ & $5(3.4)$ \\
\hline Influenza & $5(3.3)$ & $1(0.7)$ \\
\hline $\begin{array}{l}\text { Upper respiratory } \\
\text { tract infection }\end{array}$ & $5(3.3)$ & $3(2.0)$ \\
\hline $\begin{array}{l}\text { Urinary tract } \\
\text { infection }\end{array}$ & $4(2.6)$ & $4(2.7)$ \\
\hline Gastroenteritis & $4(2.6)$ & $2(1.4)$ \\
\hline Pneumonia & $4(2.6)$ & $3(2.0)$ \\
\hline Cystitis & $3(2.0)$ & $2(1.4)$ \\
\hline
\end{tabular}

Table 2 continued

\begin{tabular}{|c|c|c|}
\hline & $\begin{array}{l}\text { Tiotropium } \\
5 \mu \mathrm{g} \\
(n=151)\end{array}$ & $\begin{array}{l}\text { Tiotropium/ } \\
\text { olodaterol } 5 / 5 \mu \mathrm{g} \\
(n=148)\end{array}$ \\
\hline Pharyngitis & $3(2.0)$ & $2(1.4)$ \\
\hline $\begin{array}{l}\text { Respiratory, thoracic } \\
\text { and mediastinal } \\
\text { disorders }\end{array}$ & $46(30.5)$ & $42(28.4)$ \\
\hline COPD & $33(21.9)$ & $30(20.3)$ \\
\hline Dyspnoea & $7(4.6)$ & $2(1.4)$ \\
\hline Cough & $4(2.6)$ & $2(1.4)$ \\
\hline $\begin{array}{l}\text { Nervous system } \\
\text { disorders }\end{array}$ & $11(7.3)$ & $6(4.1)$ \\
\hline Headache & $5(3.3)$ & $1(0.7)$ \\
\hline Cardiac disorders & $7(4.6)$ & $7(4.7)$ \\
\hline Atrial fibrillation & $3(2.0)$ & $1(0.7)$ \\
\hline Vascular disorders & $8(5.3)$ & $5(3.4)$ \\
\hline Hypertension & $6(4.0)$ & $3(2.0)$ \\
\hline $\begin{array}{l}\text { Gastrointestinal } \\
\text { disorders }\end{array}$ & $26(17.2)$ & $12(8.1)$ \\
\hline Nausea & $4(2.6)$ & $0(0.0)$ \\
\hline Diarrhoea & $3(2.0)$ & $2(1.4)$ \\
\hline Vomiting & $3(2.0)$ & $2(1.4)$ \\
\hline
\end{tabular}

A patient may be counted in more than one seriousness criterion. Percentages are calculated using total number of patients per treatment as the denominator

$\mathrm{AE}$, adverse event; COPD, chronic obstructive pulmonary disease

tiotropium monotherapy (odds ratio $2.43 \pm 0.77$, indicating a relative increase of $143 \%$ in the likelihood of achieving an $\mathrm{FEV}_{1}$, TDI or SGRQ response with tiotropium/olodaterol versus tiotropium; $P=0.0046$ ). Data from the current analysis are consistent with the results from the overall populations reported in the individual study publications, suggesting that the benefits of tiotropium/ olodaterol compared with tiotropium are observed across a range of COPD patients, 
including those previously treated with LAMA monotherapy prior to study entry $[10,22]$.

Despite the effectiveness shown with LAMA or LABA monotherapy, many patients remain symptomatic on these treatments [9-13], which can in turn impact daily living activities. Avoidance of physical activity to prevent dyspnoea can lead to deconditioning, thus further reducing patient activity and causing a downward spiral associated with worse patient outcomes $[28,29]$. Patients with COPD who have some level of regular physical activity have lower risks of COPDrelated hospital admissions and mortality [29]. Patient evaluations should include exploration of symptoms by incorporating specialised tools, such as a short patient-centred questionnaire, to assess symptom severity, activity limitation and health-related quality of life [30]. In clinical practice, the COPD Assessment Test is currently one of the most useful and practical questionnaires [30]. Using the results from these tools, individual patient treatment plans should be reassessed and additional therapies added to optimise treatment [12].

In support of the current study, similar findings have been shown in other studies comparing LAMA monotherapy with LAMA/LABA in patients with COPD $[2,19,20,23,31]$. In a recent systematic literature review and metaanalysis by Han et al. [32], patients treated with LAMA/LABA showed a 0.1271 (95\% CI 0.108, $0.145 ; P<0.01)$ improvement in $\mathrm{FEV}_{1}$ area under the time curve $0-3 \mathrm{~h}$ post-dose at 12 weeks versus tiotropium. LAMA/LABA therapy also significantly improved the SGRQ total score at 12 weeks compared with tiotropium (improvement of 1.87 points; $95 \%$ CI $-2.72,-1.02$; $P<0.01)$ and increased the SGRQ responder rate by $19 \%$ [32]. However, the studies in this metaanalysis included patients on different background therapies, such as ICS, which could influence the overall results [32]. In the current analysis, the confounding effects of previous therapies are removed, enabling a cleaner comparison of the impact of escalation from one bronchodilator to two bronchodilators and indicating significant improvements in trough FEV $_{1}$, SGRQ and TDI after 12 weeks with tiotropium/olodaterol compared with tiotropium monotherapy.
Post hoc analyses of clinical trials have been conducted comparing LAMA/LABA combinations to long-acting bronchodilator monotherapies and also in various patient subgroups, including 'treatment-naïve' COPD patients who were previously not receiving any inhaled maintenance treatment. These analyses have shown similar results to the overall study population, with additional benefits for LAMA/ LABA treatment across a range of lung function endpoints and patient-reported outcomes [33-36]. Such analyses have been used to provide evidence in the debate of whether to start COPD therapy with a LAMA/LABA or monotherapy [33-36]. The current analysis utilises large clinical trial data sets to address a question that is relevant to clinical practice; namely, what is the clinical benefit of treatment escalation from LAMA to LAMA/LABA?

Donohue et al. reported that only approximately one-third of patients displayed a pronounced lung function response to both longacting bronchodilator classes, highlighting the between-patient variation in response to different bronchodilators [37]. The current analysis provides information from a large pooled data set for treatment escalation responses on lung function and patient-reported outcomes, and the responder analysis supports the escalation step from LAMA to LAMA/LABA. However, as in the study by Donohue et al. [37], clinical benefit will vary between individuals.

Previously, some safety concerns have been raised with use of dual bronchodilation in COPD [38-40]. However, our analysis of the TONADO and OTEMTO studies identified comparable safety profiles for the tiotropium and tiotropium/olodaterol treatment arms, presenting no specific concerns and indicating that stepping up from monotherapy to dual therapy is not met with an adverse safety profile. This is in agreement with previous studies evaluating the safety of tiotropium/olodaterol $[2,9,10,22,41-43]$. In the individual studies, no increase in major adverse cardiac events was observed between tiotropium/olodaterol and its monocomponents $[10,41]$. In a previous pooled analysis of TONADO and OTEMTO, the incidence of AEs was similar between treatment groups [2]; in OTEMTO, more AEs leading to 
treatment discontinuation were present in the placebo groups compared with the treatment groups, while in TONADO, AEs were similar across the treatment groups, ranging from 73\% to $77 \%$ [2]. In a separate pooled analysis of these studies, no additional safety concerns were identified in older patients using tiotropium/ olodaterol [44].

The current analysis pools data from four clinical trials, representing a large, clinically relevant patient population and allowing analysis of patients with COPD who were using LAMA monotherapy at baseline. However, these results have limitations due to the post hoc nature of the analysis and are therefore not powered for statistical comparisons, but nevertheless provide clinical value in the absence of any prospective data. At baseline, significant differences between the treatment arms were identified for weight and smoking status, but sensitivity analyses controlling for these covariates did not alter the presented results. This analysis also focuses on a subgroup of patients from the original studies that may not be fully representative of a wider COPD population.

\section{CONCLUSION}

Stepping up treatment to once-daily tiotropium/olodaterol led to significant improvements in lung function, dyspnoea severity and health status compared with tiotropium alone in patients with COPD who were receiving LAMA therapy at baseline. This shows that patients benefitted from maximising bronchodilation and treatment optimisation with tiotropium/olodaterol. Dual bronchodilation could provide additional benefits for patients with COPD currently on LAMA monotherapy and can be considered at initiation of maintenance therapy for patients with COPD.

\section{ACKNOWLEDGEMENTS}

We thank the participants included in these studies. Dave Singh is supported by the National
Institute for Health Research (NIHR) Manchester Biomedical Research Centre (BRC).

Funding. Support for this project and the journal's Rapid Service and Open Access Fees were funded by Boehringer Ingelheim International GmBH.

Medical Writing Assistance. Medical writing assistance, in the form of the preparation and revision of the manuscript, was supported financially by Boehringer Ingelheim and provided by Paul Todd at MediTech Media, under the authors' conceptual direction and based on feedback from the authors.

Authorship. The authors meet criteria for authorship as recommended by the International Committee of Medical Journal Editors (ICMJE). They take full responsibility for the scope, direction, content of and editorial decisions relating to the manuscript, were involved at all stages of development and have approved the submitted manuscript.

Authorship Contributions. The authors received no compensation related to the development of the manuscript. The authors thank Florian Voß for providing additional analyses included in this manuscript.

Prior Presentation. This manuscript is based on work previously presented as a poster at European Respiratory Society (ERS) International Congress, 28 September-02 October 2019, Madrid, Spain.

Disclosures. Roland Buhl reports personal fees from AstraZeneca, Boehringer Ingelheim, Chiesi, Cipla, Novartis, Roche, Sanofi and Teva and grants to Johannes Gutenberg University Mainz from Boehringer Ingelheim, GlaxoSmithKline, Novartis and Roche, outside the submitted work. Dave Singh reports personal fees from Apellis, Cipla, Genentech, Peptinnovate and Skyepharma and grants and personal fees from AstraZeneca, Boehringer Ingelheim, Chiesi, Glenmark, Merck, Mundipharma, Novartis, Pfizer, Pulmatrix, Teva, Theravance and Verona, outside the submitted 
work. DS is supported by the National Institute for Health Research (NIHR) Manchester Biomedical Research Centre (BRC). Alberto de la $\mathrm{Hoz}$ and Wenqiong Xue are both employees of Boehringer Ingelheim. Gary T. Ferguson has received grants, personal fees and non-financial support from Boehringer Ingelheim, Novartis, AstraZeneca, Pearl Therapeutics and Sunovion, grants and personal fees from Theravance and personal fees from Verona, Mylan, Innoviva, GlaxoSmithKline and Circassia outside the submitted work.

Compliance with Ethics Guidelines. Both the TONADO $^{\circledR}$ and OTEMTO ${ }^{\circledR}$ studies were performed in accordance with the Declaration of Helsinki, International Conference on Harmonisation Harmonised Tripartite Guideline for Good Clinical Practice and local regulations. The protocols were approved by the authorities and the ethics committees of the respective institutions, and signed informed consent was obtained from all patients.

Data Availability. The data set used and analysed during the current study are available from the corresponding author on reasonable request.

Open Access. This article is licensed under a Creative Commons Attribution-NonCommercial 4.0 International License, which permits any non-commercial use, sharing, adaptation, distribution and reproduction in any medium or format, as long as you give appropriate credit to the original author(s) and the source, provide a link to the Creative Commons licence, and indicate if changes were made. The images or other third party material in this article are included in the article's Creative Commons licence, unless indicated otherwise in a credit line to the material. If material is not included in the article's Creative Commons licence and your intended use is not permitted by statutory regulation or exceeds the permitted use, you will need to obtain permission directly from the copyright holder. To view a copy of this licence, visit http://creativecommons.org/licenses/bync/4.0/.

\section{REFERENCES}

1. Ford ES. Trends in mortality from COPD among adults in the United States. Chest. 2015;148(4): 962-70.

2. Ferguson GT, Karpel J, Bennett N, et al. Effect of tiotropium and olodaterol on symptoms and patient-reported outcomes in patients with COPD: results from four randomised, double-blind studies. NPJ Prim Care Respir Med. 2017;27(1):7.

3. Bousquet J, Khaltaev N. Global surveillance, prevention and control of chronic respiratory diseases: a comprehensive approach. Geneva: World Health Organization; 2007.

4. Lozano R, Naghavi M, Foreman K, et al. Global and regional mortality from 235 causes of death for 20 age groups in 1990 and 2010: a systematic analysis for the Global Burden of Disease Study 2010. Lancet. 2012;380(9859):2095-128.

5. Viniol C, Vogelmeier CF. Exacerbations of COPD. Eur Respir Rev. 2018;27(147):170103.

6. World Health Organization. The top 10 causes of death. 2018. https://www.who.int/en/news-room/ fact-sheets/detail/the-top-10-causes-of-death. Accessed 7 Nov 2019.

7. Casaburi R, Mahler DA, Jones PW, et al. A long-term evaluation of once-daily inhaled tiotropium in chronic obstructive pulmonary disease. Eur Respir J. $2002 ; 19(2): 217-24$.

8. Global Initiative for Chronic Obstructive Lung Disease. Global strategy for the diagnosis, management, and prevention of chronic obstructive pulmonary disease-2020 report. 2019. https:// goldcopd.org/wp-content/uploads/2019/11/GOLD2020-REPORT-ver1.0wms.pdf. Accessed 7 Nov 2019.

9. Malerba M, Foci V, Patrucco F, et al. Single inhaler LABA/LAMA for COPD. Front Pharmacol. 2019;10: 390.

10. Buhl R, Maltais F, Abrahams R, et al. Tiotropium and olodaterol fixed-dose combination versus mono-components in COPD (GOLD 2-4). Eur Respir J. 2015;45(4):969-79.

11. Price D, West D, Brusselle G, et al. Management of COPD in the UK primary-care setting: an analysis of real-life prescribing patterns. Int J Chronic Obstr Pulm Dis. 2014;9:889-904.

12. Global Initiative for Chronic Obstructive Lung Disease. COPD diagnosis, management and prevention-2019 strategy. 2018. https://www. 
guidelines.co.uk/respiratory/gold-copd-2019strategy/454454.article. Accessed 7 Nov 2019.

13. Halpin DMG. The role of tiotropium + olodaterol dual bronchodilator therapy in the management of chronic obstructive pulmonary disease. Tuberculosis Respir Dis. 2018;81(1):13-8.

14. Nici L, Mammen MJ, Charbek E, et al. Pharmacologic management of COPD: an official American Thoracic Society clinical practice guideline. Am J Respir Crit Care Med. 2020;201(9):e56-e69.

15. National Institute for Health and Care Excellence. Chronic obstructive pulmonary disease in over $16 \mathrm{~s}$ : diagnosis and management. 2019. https://www. nice.org.uk/guidance/ng115/chapter/

Recommendations\#ftn.footnote_3. Accessed 9 April 2020.

16. O'Donnell DE, Fluge T, Gerken F, et al. Effects of tiotropium on lung hyperinflation, dyspnoea and exercise tolerance in COPD. Eur Respir J. 2004;23(6):832-40.

17. Boehringer Ingelheim Limited. Spiolto Respimat 2. 5 microgram/2.5 microgram, inhalation solutionsummary of product characteristics. 2017. https:// www.medicines.org.uk/emc/medicine/30495. Accessed 6 Nov 2019.

18. Boehringer Ingelheim. New advance in COPD maintenance treatment, Spiolto ${ }^{\circledR}$ Respimat ${ }^{\circledR}$, approved in first European countries [press release]. 2015. https://www.boehringer-ingelheim.com/ press-release/new-advance-copd-maintenancetreatment-spiolto-respimat-approved-firsteuropean. Accessed 31 Oct 2019.

19. Alvarado-Gonzalez A, Arce I. Tiotropium bromide in chronic obstructive pulmonary disease and bronchial asthma. J Clin Med Res. 2015;7(11): 831-9.

20. Cazzola M, Rogliani P, Ora J, Matera MG. Olodaterol + tiotropium bromide for the treatment of chronic obstructive pulmonary disease. Expert Rev Clin Pharmacol. 2015;8(5):529-39.

21. Boehringer Ingelheim. FDA approves Stiolto ${ }^{\circledR}$ Respimat $^{\circledR}$ supplemental New Drug Application (sNDA) to add data on COPD exacerbation reduction. 2018. https://www.boehringer-ingelheim.us/ press-release/fda-approves-stiolto-respimatsupplemental-new-drug-application-snda-add-datacopd. Accessed 31 Oct 2019.

22. Singh D, Ferguson GT, Bolitschek J, et al. Tiotropium + olodaterol shows clinically meaningful improvements in quality of life. Respir Med. 2015;109(10):1312-9.
23. Vincken W, Aumann J, Chen H, Henley M, McBryan D, Goyal P. Efficacy and safety of coadministration of once-daily indacaterol and glycopyrronium versus indacaterol alone in COPD patients: the GLOW6 study. Int J Chronic Obstr Pulm Dis. 2014;9:215-28.

24. Witek TJ Jr, Mahler DA. Minimal important difference of the transition dyspnoea index in a multinational clinical trial. Eur Respir J. 2003;21(2): 267-72.

25. Wedzicha JA, Decramer M, Ficker JH, et al. Analysis of chronic obstructive pulmonary disease exacerbations with the dual bronchodilator QVA149 compared with glycopyrronium and tiotropium (SPARK): a randomised, double-blind, parallelgroup study. Lancet Respir Med. 2013;1(3): 199-209.

26. Jones PW, Beeh KM, Chapman KR, Decramer M, Mahler DA, Wedzicha JA. Minimal clinically important differences in pharmacological trials. Am J Respir Crit Care Med. 2014;189(3):250-5.

27. Thomas M, Halpin DM, Miravitlles M. When is dual bronchodilation indicated in COPD? Int J Chronic Obstr Pulm Dis. 2017;12:2291-305.

28. Watz H, Waschki B, Meyer T, Magnussen H. Physical activity in patients with COPD. Eur Respir J. 2009;33(2):262-72.

29. Vorrink SN, Kort HS, Troosters T, Lammers JW. Level of daily physical activity in individuals with COPD compared with healthy controls. Respir Res. 2011;12:33.

30. van der Molen T, Miravitlles M, Kocks JW. COPD management: role of symptom assessment in routine clinical practice. Int J Chronic Obstr Pulm Dis. 2013;8:461-71.

31. Mahler DA, D’Urzo A, Bateman ED, et al. Concurrent use of indacaterol plus tiotropium in patients with COPD provides superior bronchodilation compared with tiotropium alone: a randomised, double-blind comparison. Thorax. 2012;67(9): 781-8.

32. Han MK, Ray R, Foo J, Morel C, Hahn B. Systematic literature review and meta-analysis of US-approved LAMA/LABA therapies versus tiotropium in moderate-to-severe COPD. NPJ Prim Care Respir Med. 2018;28(1):32.

33. Muro S, Yoshisue H, Kostikas K, Olsson P, Gupta P, Wedzicha JA. Indacaterol/glycopyrronium versus tiotropium or glycopyrronium in long-acting bronchodilator-naive COPD patients: a pooled analysis. Respirology. 2020;25(4):393-400. 
34. Maleki-Yazdi MR, Singh D, Anzueto A, Tombs L, Fahy WA, Naya I. Assessing short-term deterioration in maintenance-naive patients with COPD receiving umeclidinium/vilanterol and tiotropium: a pooled analysis of three randomized trials. Adv Ther. 2017;33(12):2188-99.

35. Bjermer LH, Kerwin E, Maltais F, et al. Comparative efficacy and safety of umeclidinium/vilanterol, umeclidinium and salmeterol in symptomatic maintenance-naïve and maintenance-treated chronic obstructive pulmonary disease: a pre-specified secondary analysis of the EMAX trial. Am J Respir Crit Care Med. 2019;199:A3317.

36. Singh D, D'Urzo AD, Donohue JF, et al. An evaluation of single and dual long-acting bronchodilator therapy as effective interventions in maintenance therapy-naïve patients with COPD. Int J Chronic Obstr Pulm Dis. 2019;14:2835-48.

37. Donohue JF, Singh D, Munzu C, Kilbride S, Church A. Magnitude of umeclidinium/vilanterol lung function effect depends on monotherapy responses: results from two randomised controlled trials. Respir Med. 2016;112:65-74.

38. Lopez-Campos JL, Carrasco Hernandez L, Munoz X, Bustamante V, Barreiro E. Current controversies in the stepping up and stepping down of inhaled therapies for COPD at the patient level. Respirology. 2018;23(9):818-27.

39. Rogliani P, Matera MG, Ritondo BL, et al. Efficacy and cardiovascular safety profile of dual bronchodilation therapy in chronic obstructive pulmonary disease: a bidimensional comparative analysis across fixed-dose combinations. Pulm Pharmacol Ther. 2019;59:101841.

40. Rogliani P, Matera MG, Ora J, Cazzola M, Calzetta L. The impact of dual bronchodilation on cardiovascular serious adverse events and mortality in COPD: a quantitative synthesis. Int J Chronic Obstr Pulm Dis. 2017;12:3469-85.

41. Calverley PMA, Anzueto AR, Carter K, et al. Tiotropium and olodaterol in the prevention of chronic obstructive pulmonary disease exacerbations (DYNAGITO): a double-blind, randomised, parallel-group, active-controlled trial. Lancet Resp Med. 2018;6(5):337-44.

42. Derom E, Brusselle GG, Joos GF. Efficacy of tiotropium-olodaterol fixed-dose combination in COPD. Int J Chronic Obstr Pulm Dis. 2016;11: 3163-77.

43. Beeh KM, Westerman J, Kirsten AM, et al. The 24-h lung-function profile of once-daily tiotropium and olodaterol fixed-dose combination in chronic obstructive pulmonary disease. Pulm Pharmacol Ther. 2015;32:53-9.

44. Ferguson GT, Karpel JP, Clerisme-Beaty E, Gronke L, Voss F, Buhl R. Efficacy and safety of tiotropium + olodaterol maintenance treatment in patients with COPD in the TONADO $^{\circledR}$ and OTEMTO $^{\circledR}$ studies: a subgroup analysis by age. Int J Chronic Obstr Pulm Dis. 2016;11:2701-10. 